This item was submitted to Loughborough's Research Repository by the author.

Items in Figshare are protected by copyright, with all rights reserved, unless otherwise indicated.

\title{
National Qualifications Frameworks: developing research perspectives
}

PLEASE CITE THE PUBLISHED VERSION

http://dx.doi.org/10.1080/13538320903343099

\section{PUBLISHER}

(c) Taylor \& Francis

\section{VERSION}

SMUR (Submitted Manuscript Under Review)

\section{PUBLISHER STATEMENT}

This work is made available according to the conditions of the Creative Commons Attribution-NonCommercialNoDerivatives 4.0 International (CC BY-NC-ND 4.0) licence. Full details of this licence are available at: https://creativecommons.org/licenses/by-nc-nd/4.0/

\section{LICENCE}

CC BY-NC-ND 4.0

\section{REPOSITORY RECORD}

Fernie, Scott, and Nick Pilcher. 2019. "National Qualifications Frameworks: Developing Research Perspectives". figshare. https://hdl.handle.net/2134/17720. 


\title{
NQF: developing research perspectives
}

\author{
Scott Fernie ${ }^{1}$ \\ s.fernie@hw.ac.uk
}

Nick Pilcher ${ }^{2}$

N.Pilcher@hw.ac.uk

\footnotetext{
${ }^{1}$ School of the Built Environment, Heriot-Watt University, Edinburgh, Scotland

${ }^{2}$ School of Marketing, Tourism and Languages, Edinburgh Napier University, Edinburgh, Scotland
} 


\section{Abstract}

Arguments for National Qualification Frameworks (NQF) are compelling (NICHE 1997). Indeed, such frameworks are now an international phenomenon. Yet, few studies take a critical perspective and challenge the broad assumptions underpinning NQF. Arguments presented in this paper attempt to open a debate within the HE community that draws attention to conflicts and tensions regarding the diffusion and use of NQF. The emphasis of the debate is on the use of the Scottish Credit and Qualification Framework (SCQF) within Higher Education. The SCQF is used in this paper as an exemplar to explore and highlight these conflicts and tensions. The critique is based on a historical and managerialist view which forms the basis of a number of research propositions regarding the future of NQF. Specifically, four distinct yet interrelated research perspectives requiring future attention are proposed: political; innovation-diffusion; normative; and consistency. Such perspectives are argued to provide a more robust and reliable basis for developing NQF. The paper thus contextualises the SCQF within the recent 'global tsunami' of NQF and uses the SCQF as an exemplar to open up a wider debate about NQF.

\section{Biographical Notes}

Dr Nick Pilcher is a Lecturer at Edinburgh Napier University. His research interests are experiences of learning, dissertations, pedagogical practice and qualitative inquiry. 
Dr Scott Fernie is a Lecturer at Heriot-Watt University. His research interests relate to managerial practice, the diffusion of innovation, change, structuration theory and educational policy.

\section{Introduction}

"And it ought to be remembered that there is nothing more difficult to take in hand, more perilous to conduct, or more uncertain in its success, than to take the lead in the introduction of a new order of things. Because the innovator has for enemies all those who have done well under the old conditions, and lukewarm defenders in those who may do well under the new. This coolness arises partly from fear of the opponents, who have the laws on their side, and partly from the incredulity of men, who do not readily believe in new things until they have had a long experience of them.” (Machiavelli 1532 Chapter IV)

The Machiavelli quote above is used here to focus the attention of the debate upon innovation and innovation diffusion. Critical research that engages with a view of NQF as innovation has much to offer in that it can reveal areas for future development that would not be revealed by purely evaluative research (cf Alkin and Taut 2003). There is also a broad and well developed body of innovation research from which to draw upon. Indeed, any NQF easily fits with Rura-Polley and Clegg's (1999) view of an administrative innovation. Administrative innovations differ from technological innovations but are no less socially complex to diffuse within social settings. NQF as an innovation are therefore likely to directly challenge existing structures, frameworks and 
practices. The diffusion of NQF in a number of disparate educational contexts around the world is gathering pace and thus these challenges are extremely important to both recognize and learn from.

The attention of this critique is on the SCQF and focuses upon the HE sector. This does not exclude the primary, secondary and further education sectors from the relevance of the critique. Indeed, some of the greatest challenges within the framework arguably lie at the borders between primary, secondary, further and higher education. An attempt is made within the paper to locate the SCQF within a broad historical and political context. This context provides a backdrop to the paper's subsequent managerial critique of the SCQF. What is explored is hitherto ill exposed debates surrounding the development and diffusion of NQF by using the SCQF as an exemplar of what is referred to by the authors as a 'global tsunami' of $\mathrm{QF}^{3}$. In this sense, though some of the findings may be uniquely Scottish, they have resonance and relevance to other contexts and in particular the development of a European Qualifications Framework (EQF).

Bt taking the assumption that SCQF is an administrative innovation, it must inevitably be considered a new order of things. As such, according to the Machiavelli quote used previously, its development and diffusion will be nothing short of problematic, political and even perilous. Insights into why and for whom it is problematic, political or perilous are extremely difficult to ascertain in the absence of focused critique, academic inquiry,

\footnotetext{
${ }^{3}$ This global tsunami refers to the ongoing development of QF around the globe e.g. Australia, Namibia, Switzerland, South Africa, Ontario, Malaysia, New Zealand, etc...
} 
and open debate. The intention of the paper is to provide the basis for such critique, inquiry and debate.

The paper is divided into three separate sections. The first explains and explores the global rise of NQF and seeks to position the SCQF within its wider context. The second section explores and critiques the SCQF as an exemplar of NQF and as an administrative innovation. The third section of the paper proposes future research perspectives for NQF that draw from the previous sections. The conclusions call for greater depth and critical analysis within the research community regarding NQF. The overall intention of the paper is to provide a critical voice within the body of NQF research.

\section{NQF: Background}

Given the current momentum and rise of NQF (Blackmur 2004) their development looks set to continue well into the future. NQFs must also not be disconnected from a wider political context and what Naylor (2007) describes as an ongoing desire to massify the education system. Similarly, NQF also appear to be driven by the desire for a 'knowledge economy’ (DTI 1998) and, what Olssen and Peters (2005) highlighted as the assumed links between this economy and the productivity of the education sector. This is not to question the legitimacy of a goal to massify the education system or criticise a shift towards a knowledge economy but rather to make explicit a need to recognise that these cannot be ignored as shaping influences on administrative innovations such as the SCQF. Indeed, any process of inquiry that focuses upon innovations within the public sector cannot ignore such wider political contextual influences. It is also arguable whether such influences are reflected and reinforced by the SCQF. 
Despite this, inquiries into NQFs are largely prescriptive and evaluative rather than what Alkin and Taut (2003) describe as being research based. In essence, most previous research takes for granted the underlying assumptions of NQF by investigating them from a purely evaluative perspective that does not have what Alkin and Taut (2003) describe as a research based investigative gaze. Although each type of research has its merits, research into NQF needs a balance of both. However, critical research that challenges the underpinning assumptions of NQF remains limited. Further, most studies that have been done are funded by bodies aiming to develop and further NQFs, and are thus evaluative (e.g. Gallacher et al. 2005) not research based. Nevertheless, recent research based studies such as Blackmur (2004) begin to open up and widen views of NQF by exploring underpinning managerialist rhetoric. Such studies provide support for further critical research to address contexts and issues from alternative theoretical perspectives in order to develop more robust and effective NQF; or indeed, present opportunities for alternative policy directions.

NQF can be viewed to have many core aims: provide wider access to the education sector for massification and life-long learning; develop a robust exchange rate mechanism for cross country student mobility; facilitate homogenization of standards in an international context for equivalency; and the development of a reliable basis for this homogenization through quality assured frameworks - NQF. Nevertheless, the view that NQF are intended to transform education is not common. Indeed, it is stated in the SCQF that it is not meant to be transformative (Gallacher et al. 2005). However, if the key core aims of NQF are 
accepted, NQF cannot be anything but transformative; i.e. aiming to have wider access, an exchange rate mechanism and homogenization would imply that these things were not previously delivered through education and thus, arguably education needs to be transformed.

In a wider educational context, it can be argued that NQFs for HEIs bolt onto existing primary and secondary educational 'frameworks' and curricula. In the UK, The National Curriculum in England was introduced in the early 1990s but is continually being added to (e.g. the introduction of PE and citizenship by September 2009 to all year 10 students). Also, Learning and Teaching Scotland has developed a 5-14 curriculum over many years starting again in the early 1990s. The International Baccalaureate (Ashforth and Gibbs) also connects with the ongoing development of EQF and thus by extension other EU based educational frameworks such as the SCQF. Thus, any NQF under development must arguably be highly sensitive to the IB, and by implication, to any other preuniversity education curricula. In addition, the notion of an EQF must take account of the knowledge and ability level of students that study the IB. There must also be a symbiotic relationship between the EQF, any European NQF, and any primary and secondary frameworks and curricula. The EQF cannot therefore be isolated from debates and discussions of NQF development and diffusion, and vice versa. They are in a recursive relationship.

Indeed, the SCQF cannot be considered in isolation from the ongoing development of EQF. The SCQF is but one NQF that will arguably shape and be shaped by the EQF. It is 
expected that through harmonisation and homogenization processes, EU based NQF will ostensibly be connected through the EQF by 2010. Following this, by 2012, there is an expectation that each member state will be required to "ensure that individual qualification certificates bear a reference to the appropriate EQF level” (EC 2008). NQF are therefore arguably intended to have the role of centralising qualifications. The extent to which this means controlling qualifications is debatable, and might prove highly controversial. However, it is argued here that the EQF will act as a gatekeeper for new qualifications and will thus be a controlling mechanism. At a European level, the development of HEI NQF, such as SCQF, cannot be disconnected from a number of other influential political movements to centralise and regulate education. Such movement is unlikely to be met without resistance.

\section{NQF as innovations: the case of the SCQF}

It is, therefore, perfectly reasonable to question whether such resistance is also currently informed by the heavy hand of the past. It is generally considered necessary by historians to have a degree of temporal distance between past events and the present in order to arrive at a historical representation (Phillips 2004). It is perhaps for this reason, and the comparatively recent surge of NQF that, until now, few critical examinations of NQF have surfaced that explore resistance and underlying assumptions.

The following is a critical examination of the SCQF (as an exemplar of NQF) that expands upon and explores its underpinning assumptions. Although not exhaustive, this deconstruction highlights the main concerns and limitations frequently absent in the literature promoting and evaluating SCQF and, by implication, other NQF. Principally, 
four main areas are highlighted: contextual embeddedness; practice and action; innovation diffusion and; institutional politics. The critique connects critical voices in the managerial and innovation literature to the current thoughts and mechanisms of the SCQF.

\section{SCQF: contextual embededness}

The SCQF resonates with the development of a number of other National Qualification Frameworks (NQF). In tertiary education, the fundamental aims of NQF are to develop and diffuse a regulated system to classify qualifications. Such systems attempt to provide transparency for students, industry and academics. In addition, NQF also facilitate mapping qualifications from one country to another and thus provide transparency for international recruitment staff, and overseas students - the internationalisation of education. The assumption that it is possible to "give an assurance [in a national or international context] about what a person is competent to do" (Randall 2000) is a move towards a normative regulatory framework within which qualifications are portable (Heise 1998) - a form of 'exchange rate mechanism'.

Such a mechanism at an international level would have to be highly sensitive to the contexts within which qualifications are exported and imported. A lack of sensitivity in this respect could lead to what one critique of functionalist methods of inquiry revealed as context stripping (Guba and Lincoln 1998). The focus on 'learning outcomes' in NQF and the SCQF therefore risks excluding how the impact of national educational policy, political motivations, culture, history and economics shape the underpinning assumptions of qualifications. NQF and SCQF ultimately represent an attempt to benchmark 
qualifications but unfortunately seem to have neglected critiques of benchmarking that highlight the issue of context stripping (Wolfram Cox et al. 1997). Thus, any single qualification located within a NQF is rooted in a context that an emphasis solely on 'generic learning outcomes' cannot capture. More important, however, is the criticism surrounding the relevance of one NQF to another. Contextually stripping potentially important factors from one NQF limits the transferability or generalisability of the findings to other contexts. In other words, the portability of qualifications from one NQF to another is highly problematic since the differences in context may be insurmountable. What is proposed in the knowledge sharing literature to remedy this problem is ‘recontextualisation’ by Gavigan et al. (1999), Thomson et al. (2001) and Hull (2000). These authors highlight the dangers of disconnecting knowledge (a qualification for example) from host and receiving contexts (Fernie et al. 2003). A failure to understand and relate initiatives to context is fundamental in explaining why organizational change consistently fails to deliver (Beer et al. 1993). If it is accepted that the SCQF is change orientated (transformative), it is therefore essential that context is recognised as influential. Indeed, if portability of qualifications is the goal of NQF policy makers, then an acontextual normative framework such as the SCQF may not be the most productive way forward. Indeed, it may even be counter productive.

\section{SCQF: challenging academic practice and action}

There is a broad objective in the education sector regarding widening access to education. This can arguably be achieved by opening up the system to broader social groups and/or to all ages - widening participation (HEFCE 2008). This aim resonates with the ongoing trend of worldwide education system expansion or 'massification' (Guri-Rosenblit et al. 
2007). The assumption here is that this worldwide education system will benefit from the clear, transparent levels and descriptions NQF provide for underpinning qualifications. There is also another assumption that this worldwide education system will benefit from the student mobility that an NQF ostensibly facilitates.

However, for academics concerned with providing a high quality education to students or for those charged with the responsibility to defend and maintain standards, such growth in student numbers as a consequence of massification may arguably be seen to provide tensions rather than opportunities. The consequences of growth must therefore be fully and widely critiqued. Notably, if NQF such as the SCQF are not robust and reliable, then entrants who are accepted through the use of the framework may not have been robustly or reliably entered, and those who leave the framework may not have been robustly or reliably assessed. Consequently, underpinning the SCQF is its key assumed ability to provide a robust and reliable basis for academic standards across diverse groups of students whilst simultaneously facilitating access to the education system for these students. It is therefore essential to view such an assumption within the wider context of academic practice and whether or not there exist inherent conflicts and tensions.

Academic standards are arguably inherent in the text used to describe 'characteristic generic outcomes' at each level of the SCQF. Additionally, it is stated that the SCQF is designed - to clarify entry and exit points, and routes for progression (SCQF 2001) or standards. For admission tutors, the SCQF firstly provides a robust framework to ensure standards of students entering and exiting the system, and secondly, a wider platform for 
recruiting students onto courses - growth. For academics responsible for curriculum development, the SCQF is meant to be heavily drawn upon and referred to frame and assess programmes, courses and modules. It is therefore also intended to underpin and inform teaching approaches and frame standards for academics. Notwithstanding module and course leaders' practice being shaped by the SCQF, the activities and practice of the external examiners on a course in Scotland should, arguably, be heavily influenced by the SCQF. If academic standards are connected to SCQF levels then the SCQF is an influential framework within the external examining system. Lending weight to the power of the SCQF to be highly influential, it must also be assumed that professional bodies accrediting courses in Scotland will have had a role to play in the development of the SCQF and its application in practice. Their requirements will be mediated through the SCQF or at least the SCQF should not be in conflict with professional bodies expectations of graduates.

Thus, it would appear that academics using the SCQF must place a significant amount of confidence in the admissions system to similarly place the SCQF at the heart of their processes, practices and procedures. Similarly, external examiners will place confidence in the admissions system that it is recruiting students according to the entry and exit points set by the SCQF, and that lecturers are developing teaching material and assessment processes that resonate with the entry and exit points in the SCQF. Its normative properties arguably bring confidence in the system and develop trust. Any institution that fails to embed the SCQF within all aspects of the university undoubtedly runs the risk of the opposite - creating tension and friction between lecturers (ethics, 
morals, practice and principles) and the 'organisational system'. It is therefore necessary to question whether the SCQF is similarly interpreted by all stakeholders within a single university.

Notably, knowledge and understanding of the SCQF across interest groups has been found to be uneven and practitioners using the SCQF have expressed significant concern that the SCQF "encouraged unrealistic expectations regarding the potential for the framework to introduce change" (Gallacher et al. 2005). To what extent this has caused tension and friction within the education system is unclear but Alderman and Brown's (2005) view of the denigration of academic standards and the external examiner system make for intriguing reading in this respect. Research that explores the connection between Alderman and Brown's (2005) view and the role of the SCQF would clearly be highly informative and helpful.

Underlying the SCQF is also the assumption that it is similarly interpreted by stakeholders and interest groups. However, there are undoubtedly any number of motivations to explain why one interest group may obstruct change (Marchington and Grugulis 1998) and indeed why others may embrace it fully. Underpinned by the concept of resonance (Hodder 1998) in the innovation literature, it would appear to be a taken for granted assumption that the SCQF resonates with the concerns and interests of all stakeholders. Organisation studies research such as that noted above would appear to challenge such a taken for granted assumption. Consequently, there are simply not enough studies exploring how the SCQF resonates with the practice of academic 
lecturers, external examiners and admission tutors. It is highly unlikely that the SCQF has not been met with resistance from stakeholders; especially academic lecturers whose practice would undoubtedly be seriously challenged by the SCQF. To what extent this resistance is articulated or formed also remains under researched - indeed do stakeholders react symbolically or substantively to the SCQF? In order to develop and deepen thinking behind NQF, it is first necessary to turn a critical gaze upon taken for granted assumptions.

\section{SCQF: Diffusion of an innovation}

The SCQF aims to provide "rationalization, not creation" (Gunning 1999) and has "no regulatory framework" (Raffe 2007). Clearly, the assumption is that the SCQF is not meant to be transformative. Arguably, it should therefore not be viewed as an 'administrative innovation' with an attendant need to focus on diffusion. However, any attempt to rationalise will indirectly have transformative properties on the practice of numerous stakeholders and interest groups - such as admission tutors and academic lecturers. At the very least, the introduction of a new system will lead to some resistance from interest groups - something which even very positive accounts of the SCQF's implementation have noted (Raffe 2007). It is therefore inaccurate and misleading to describe the SCQF as non-transformative. Instead, the SCQF and any NQF should be considered as innovative and as such, according to Kimberley (1981), diffusion will inevitably challenge and destabilise existing interest groups and practices. Not least, the institutional power and practice of lecturers, admission tutors, external examiners, professional and quality assurance bodies. This socially complex view of diffusion is 
largely conceded within the study of innovation systems (see Rogers 1995). Therefore, an understanding of the performance of NQF must simultaneously be rooted in an understanding of the meanings and interpretations various interest groups and partnerships have of NQF as innovations.

A failure to acknowledge and explore resistance to change and any attendant social complexity renders attempts to diffuse the SCQF as potentially naïve. Practitioners and researchers who neglect the way in which the SCQF is diffused fail to ask a number of highly apposite questions such as: who has the institutional power to diffuse change; do they differ from those who have the institutional power to develop the SCQF; are stakeholders reacting symbolically or substantively to SCQF; is the SCQF being used in practice in the way it was intended or has it been reinvented through diffusion; who is resisting and why; are there any fundamental problems with the SCQF and lessons to be learnt from its diffusion; and, has it been successful? These are pressing questions for research exploring the development and diffusion of any NQF which at the moment remain absent or marginalized. A supplementary question must therefore be why? Furthermore, despite the ongoing diffusion of the SCQF, there remains concern that the "Full use of the Framework" (Raffe 2007) is an aspiration. Again, the question that must therefore be asked is why?

Given NQF proximity to the research community, it is rather surprising, or perhaps telling, that there is a lack of studies critically exploring and actively engaging with the social complexity of diffusion. This resonates with Greenwood and Levin’s (2008) 
argument of the reluctance of academic institutions (researchers) to inwardly reflect. This does not however concede that research is there to facilitate the diffusion of the SCQF, indeed, such critical reflection and research may be more illuminating in providing valid misgivings about the whole SCQF project itself. Equally, such illumination could be constructively used to help further our understanding of NQF, something critical to their diffusion.

\section{SCQF: back to politics}

To better understand the issues described above, it is necessary to explore the genesis of the SCQF in its political context. At the heart of politics and education is the pivotal white paper 'the knowledge economy' (DTI 1998). This is argued to need a labour force with high levels of transferable skills. Arguably, the SCQF helps Higher Education Institutions (HEI) to provide a system whereby students acquire such transferable skills. This will help them and the country compete in today's knowledge economy. In order to facilitate such competitive aspirations, the development of the SCQF can also be seen as part of a larger political project to centralise control of education (Filippakou and Tapper 2007). Further, this centralization of control could in the case of Scotland be viewed as integral to a desire to stamp an individual character upon the education system in Scotland post- devolution. Yet, historically, the extent to which this imposition of a politically motivated, top-down, centralised system in Scotland can be successful is questionable (see Morgan 1933). Indeed, evidence that this is being questioned for other NQF also exists (see Blackmur 2004). This would arguably become more clearly visible if researchers shift their gaze towards exploring such issues as: resistance to change; social complexity; the relationship between practice and action; a need for context 
sensitivity; a view that NQF are innovations that are diffused in a complex social system and; the influence of politics upon NQF.

\section{Research propositions: a discussion}

Perhaps one of the most influential ways to address the issues arising from the deconstruction above is to suggest a number of ways in which research can be influential in bringing greater intellectual rigour and debate to NQF. The research suggested is not exhaustive and is informed by the concerns, interests and institutions to which the authors belong. Others reading this paper may agree or disagree with the critical account above and may argue a case for other avenues of research - we hope this is the case. If so, the deconstruction above will have provoked thought and discussion concerning NQF and more specifically the SCQF.

It is possible to trace two main influences in the paper so far: a political deconstruction of NQF and an organisation studies perspective on NQF as innovations. This reflects the main interests of the authors at the time of writing and has thus similarly shaped the following propositions for future research using the SCQF as an exemplar. These propositions are also highly relevant to other NQF. They would however need to be very sensitive to the uniqueness of each country's educational, political, institutional and social contexts.

\section{Research perspectives and opportunities}


Leading on from this history and from these arguments and assumptions, a number of key perspectives inform our propositions. Firstly a political perspective focused on policy and strategy, i.e. whether the transformative properties of the SCQF on universities per se have been fully recognised and considered during its development. In turn, whether the intended and unintended consequences arising from these transformative properties have been fully explored. Secondly, and following on from this, an innovation diffusion perspective: i.e. whether the process of diffusing the SCQF has taken full cognisance of the potential for stakeholders and interest groups to resist this unilateral challenge to their established practice. Arguably, the SCQF will resonate more or less with stakeholders and interest groups and thus create social tension between these disparate groups. Thirdly a normative perspective: i.e. whether all operational stakeholders and interest groups (lecturers, students, overseas recruitment agencies, university admissions offices, education developers) will understand and interpret the framework similarly. It is perhaps worth noting that the use of discourse and by extension discourse analysis would be significantly relevant to studies exploring the diffusion of the SCQF. Lastly, a consistency perspective: i.e. whether the attainment of credits across different subjects equates to comparable learning outcomes. Indeed, whether credits across NQF and the broader EQF are comparable.

This section explores these key areas further and forwards possible areas for future investigation. The propositions set out below reflect the authors' views and opinions but in no way attempt to prescribe the only way(s) forward. Indeed, one of the main aims of the paper is to generate interest and attempt to get the academic community to turn a 
more critical gaze upon further development and diffusion of the SCQF and NQF more broadly; in national, trans-national and inter-national contexts. Thus, the undertone in the paper is a suggestive one where the authors readily concede and indeed encourage others to interpret the arguments above and develop their own research agenda.

\section{Political perspective}

The dominant view of the SCQF and its perilous diffusion are simplistic and fail to capture the essence of who is the innovator, who are the enemies, who are the lukewarm defenders, and what fear and incredulity needs to be overcome. Indeed, it could be argued that some do not view the SCQF as a new order of things and thus would not readily concede to the view that it is transformative and thus, according to Burnes's (2004) view of change, politically and managerially complex. In Scotland's case, that the SCQF is likely to mean many different things to a variety of stakeholders (for example the politicians, government quangos, the policy makers, vice-chancellors, and industry), and could mean that "the elaboration of these schemas [SCQF] corresponds to a whole series of diverse practices and strategies” (Foucault (1978) cited in Faubion 2000 p.232).

However, the dominant focus of investigations and evaluations concerning the SCQF take a more mechanical approach. The research questions asked are therefore not driven by a desire to explore the disparate meanings and interpretations that may be placed upon this new order of things. In other words the new order of things is presented as a fait accompli. The failure of the academic research community to turn a critical gaze upon its own institutions and structures in this respect is rather striking despite broad arguments 
from Greenwood and Levin (2008) and Rowland (2000) that such a gaze is essential. Additionally, there is a broader problem of securing funds to conduct such critical, qualitative and interpretative research (Cheek 2005; Torrance 2006).

Despite this, there are a number of strands of research which would be extremely valuable in providing robust and reliable explanations to policy makers keen to improve the SCQF and help facilitate its diffusion. Arguably, research is necessary that explores the conflicting strategic perceptions, experiences and discourses regarding: the transformative properties of the SCQF; meanings ascribed to the SCQF; the relevance and influence of the SCQF on policy and strategy; its rationale and origin; its effectiveness.

\section{Innovation diffusion perspective}

This perspective draws from previous arguments concerning the overly simplified view of the SCQF as innovation per se and by extension the socially complex nature of its diffusion. Drawing on Machiavelli, this perspective on SCQF assumes its diffusion is perilous to conduct as it is undoubtedly a new order of things. If it is accepted that the SCQF can be considered as an administrative innovation and if it is readily conceded to be socially complex then there are numerous under-explored avenues of research. These would open a debate concerning how difficult such an undertaking is to take in hand and how uncertain the success of such a risky adventure would be to undertake. Such research would provide policy makers and practitioners alike with significant knowledge and insight into the specific processes of formulating and diffusing SCQF policy and its 
impact upon practice. It would also open up a debate about the connection between policy and practice within the education sector.

It is therefore proposed that research is necessary to explore policy makers' assumptions that underpin such key areas as: the SCQF; mechanisms of diffusion; institutional power to diffuse; perception and reality of stakeholder reception and; monitoring and feedback mechanisms. Further to such research it is also considered fundamental to explorethe following: the resonance between policy and practice; resistance to change; the challenges to academic practice; consequences for policy of this resistance and; unintended consequences.

\section{A normative perspective}

At an operational level, the SCQF will similarly be subject to multiple interpretations that cannot be viewed in isolation of multiple strategic interpretations noted above in the political perspective. This reflects the conceptual space that exists between espoused theory and theory in action (Argyris and Schön 1974). This space also leaves significant room for stakeholders and interest groups at an operational level to conduct symbolic activities designed to propitiate policy makers but have little impact upon their established practice. At an operational level (for example lecturers, course/programme leaders, admissions departments, employers, and professional accrediting bodies), a normative framework overly simplifies and assumes wide consensus and agreement on the use and content inherent in the SCQF. As noted above in the political perspective, change cannot be understood to be simple and straight forward to formulate or diffuse. 
Indeed, amongst the stakeholders and interest groups there will be, coolness, fear, lukewarm defenders of the change, opponents to the change, laws both supporting and challenging the change, and incredulity on behalf of the innovator. This point was not lost on Cohen and March (1974, p206) who argue that in universities "anything that requires a co-ordinated effort of the organisation to start is unlikely to be started. Anything that requires a co-ordinated effort of the organisation in order to be stopped is unlikely to be stopped". This is arguably still the case in modern academia.

Research that explores operational stakeholder understanding of the effects of SCQF on their practice will provide deeper insights into the normative effects of the SCQF. In particular this research should explore multiple stakeholder understandings: to explore their perspective of the effects of the SCQF on their own practice (a self-perspective) and also to explore their perspective of the effects of the SCQF on others' practices (an others-perspective). Further to such research would be to explore stakeholder suggestions for the resolution of any perceived dissonance on the part of self or others. This would provide explanations that unpick the assumptions underlying SCQF's normative goals and deconstruct potential resistance and / or what Ashforth and Gibbs (1990) and Leiringer and Green (2007) refer to as symbolic activity. In addition, what the discourse and language used in stakeholder activities in relation to the SCQF is, and how this language is perceived by stakeholders at different levels. It is possible that the very language used to describe the SCQF polarizes and identifies stakeholders rather than unifies them. An exploration of the discourse and language used by operational stakeholders and interest groups will also provide significant insight into the process of 
normalization. Such research will also expose interpretations regarding what the SCQF is intended to normalise and for whose purposes and ends.

\section{Consistency perspective}

Whereas the normative perspective addresses the people involved with SCQF, the consistency perspective looks more at the components and elements of the SCQF. This perspective leads us to explore credit consistency and the validity of credit transfer across contexts, either at a subject level or a trans-national level. The emphasis on learning outcomes is pivotal to this grand objective of consistency. Such an objective surely needs to be the subject of research that explores how or whether it can be achieved through the SCQF, or indeed any NQF. Undoubtedly, any approach will have limitations associated with the assumptions made about the mechanism through which consistency will be achieved. In other words, it is necessary to explore whether or not the SCQF is pushing a square peg into a round hole. One avenue of such research would be to explore whether the SCQF is based upon a misappropriated assumption that there is a 'blank slate' of abilities that can be transferred from one subject area to another - as noted elsewhere any critical research of such blank slates frequently leads to accusations of discrimination and social change (Pinker 2002). For the purposes of this critique of the SCQF, Pinker (2002) could arguably be used to describe the difficulty of academic resistance to the diffusion of the SCQF as a mechanism for positive social change.

Arguably, as a direct result of this, the research community must challenge whether an emphasis on learning outcomes can achieve a robust and reliable basis upon which 
consistency can be achieved between subject specific credits and levels; building blocks. Such a view is also supported by Hussey and Smith (2002; 2008) who argue that learning outcomes have been misappropriated and misused. Such research could explore subject specialists' interpretations regarding the equitability of building block transferability. Indeed there are significant variables at play in such a study that necessitates research capable of dealing with significant social, technical and pedagogical complexity. Such variables include the building blocks per se, the actual abilities of the students, the lecturers' abilities to describe and deliver the blocks, and the assets and institutions within which delivery takes place. In other words, it is a call for contextual sensitivity that extends Blackmur’s (2004) philosophical criticisms of NQF.

Without such research regarding consistency it may not be possible to overcome the incredulity of men regarding the SCQF. Nor will these men (or women) readily believe in new things (SCQF) unless they can place trust in its reliability and robustness to be consistent. This assumes that such men or women are not already engaging in symbolic activity and empty rhetoric. Indeed, if they are, the research proposed under the political, diffusion and normative perspectives will provide the significant insights necessary to unpick and unpack such an assumption.

\section{Conclusions}


If we assume that the SCQF is an innovation that is both necessary and desirable for the Scottish education sector, then research that explores its ability to achieve such change is axiomatic to the success of the education sector itself. However, there is a paucity of research exploring the development and diffusion of the SCQF and NQFs more broadly. Historically, previous studies have shown tensions between the imposition of uniformity in education and resistance to this imposition from education institutions. The recent 'global tsunami' of NQF has been so swift that research has been unable to keep pace with its development and diffusion. Politics surrounding the funding of such research may also be extremely problematic. In particular, the dominance of research into the SCQF has been evaluative, and funded by the SCQF itself, and is thus unable to attain the levels of criticality and independence argued in this paper to be fundamentally necessary. Arguably, this may also be the case with other NQF. The taken for granted assumptions that the SCQF and its diffusion is unproblematic, universally welcomed and benign must be challenged. In doing so, research can begin to explore and give voice to a myriad of potentially hidden conflict, tension, controversy and confusion that are argued to exist. Additionally, rather like the ancient Babylonians whose understanding of the heavens was geocentrically rather than heliocentrically focused (Toulmin and Goodfield 1965), investigations into the SCQF or indeed NQF are argued to be mechanically focused instrumental rationality dominates as opposed to methodological pluralism.

The paper has explored and exposed numerous assumptions taken by the dominant research agenda into NQF. These assumptions related to contextual embededness, challenging academic practice and action, innovation diffusion, and politics. On the basis 
of these assumptions a number of broad perspectives and specific opportunities for research have been suggested: political; innovation diffusion; normative and consistency. Although these are undoubtedly not exhaustive They have a clear and direct relation to criticisms of instrumental rationality and the overarching paucity of critical research into NQF. The paper is not intended to be construed as overly critical, but aims to open constructive engagement between stakeholders and interest groups with a long term view to improve education and educational research. Indeed, the research suggested should be viewed as complementary to the recommendations outlined by the Garrick report (NICHE 1997) in terms of evidence-based policy making.

\section{References}

Alderman, G. and Brown, R. (2005). "Can Quality Assurance survive the market? Accreditation and audit at the crossroads." Higher Education Quarterly 59(4): 313-328. Alkin, M. C. and Taut, S. (2003). "Unbundling Evaluation Use In Studies." Educational Evaluation 29 1-12.

Argyris, M. and Schön, D. (1974). Theory in Practice. Increasing professional effectiveness. Jossey-Bass. San Francisco

Ashforth, B. E. and Gibbs, B. W. (1990). "The double-edge of organizational legitimation." Organization Science 1(2): 177-194.

Beer, M., Eisenstat, R. A. and Spector, B. (1993). Why change programs don't produce change. Managing Change. C. Mabey, Mayon-White, B. Paul Chapman Publishing London: 99-107.

Blackmur, D. (2004). "A critique of the concept of a national qualifications framework." Quality in Higher Education 10(3): 267-284.

Burnes, B. (2004). Managing change : a strategic approach to organisational dynamics. FT Prentice Hall. London

Cheek, J. (2005). The Practice and Politics of Funded Qualitative Research. The SAGE handbook of qualitative research. N. K. Denzin and Y. S. Lincoln. Sage Publications Thousand Oaks: 387-410.

Cohen, M. D. and March, J. G. (1974). Leadership and ambiguity: The American college president. McGraw Hill. New York

DTI (1998). Competitive Futures: Building the Knowledge Driven Economy. London, Department of Trade and Industry.

EC (2008). The European Qualifications Framework for Lifelong Learning (EQF). Luxembourg, Office for Official Publications of the European Communities. 
Faubion, J., D., Ed. (2000). The essential works of Foucault 1954 - 1984, Volume 3, Power. The New Press, New York.

Fernie, S., Green, S., Weller, S. and Newcombe, R. (2003). "Knowledge Sharing: Context, Confusion and Controversy." International Journal of Project Management, Special issue: Management of knowledge in project environments 21(3): 177-188.

Filippakou, O. and Tapper, T. (2007). "Quality Assurance in Higher Education: Thinking Beyond the English Experience." Higher Education Policy 20: 339-360.

Gallacher, J., Toman, N., Caldwell, J., Edwards, R. and Raffe, D. (2005). Evaluation of the impact of the Scottish Credit and Qualifications Framework (SCQF), Scottish Office Central Research Unit.

Gavigan, J. P., Ottitsch, M. and Mahroum, S. (1999). The Futures Project, Knowledge and Learning: Towards a learning Europe, European Commission Directorate - General JRC Joint Research Centre, Institute for prospective technological studies, TECS Futures programme.

Greenwood, D. J. and Levin, M. (2008). Reform of the social sciences and of universities through action research. The Landscape of Qualitative Research. D. K. Denzin and Y. S. Lincoln. Sage California.

Guba, E. G. and Lincoln, Y. S. (1998). Competing Paradigms in Qualitative Research. The Landscape of Qualitative Research: Theories and Issues. D. K. Denzin and Y. S. Lincoln. Sage Publications California.

Gunning, D. (1999). A National Qualifications framework - the Scottish Experience. Namibian Qualifications' Framework Conference, Windhoek, Namibia.

Guri-Rosenblit, S., Šebková, H. and Teichler, U. (2007). "Massification and diversity of higher education systems: Interplay of complex dimensions." Higher Education Policy 20(4): 373-389.

HEFCE (2008). Strategic plan 2006-11, Higher Education Funding Council for England (HEFCE).

Heise, W. (1998). "Portability of qualifications: an answer to the qualificational demands of globalisation." Journal of European Industrial Training 22(7): 289-300.

Hodder, I. (1998). Creative thought: a long term perspective. Creativity in Human Evolution and Prehistory. S. Mithen. Routledge London.

Hull, R. (2000). Knowledge Management and the Conduct of Expert Labour. Managing Knowledge: Critical Investigations of Work and Learning. R. H. C. Pritchard, M. Chumer and H. Willmott. MacMillan Press London.

Hussey, T. and Smith, P. (2002). "The Trouble with Learning Outcomes." Active Learning in Higher Education 3(3): 220-233.

Hussey, T. and Smith, P. (2008). "Learning outcomes: a conceptual analysis." Teaching in Higher Education 13(1): 107 - 115.

Kimberley, J. R. (1981). Managerial innovation. Handbook of Organizational Design. P. C. N. a. W. H. Starbuck. 84-104.

Leiringer, R. and Green, S. D. (2007). The substantive and symbolic management of legitimacy in PFI procurement. CIB W092: Interdisciplinarity in Built Environment Procurement conference, Hunter Valley, Australia.

Machiavelli, D. N. (1532). Il Principe. 
Marchington, M. and Grugulis, I. (1998). "Best practice human resource management: perfect opportunity or dangerous illusion?" International Journal of Human Resource Management 11(6): 1104-1124.

Morgan, A. (1933). Scottish university studies. Oxford University Press. Oxford

Naylor, R. (2007). Whose degree is it anyway? Why, How and where universities are failing our students. Pencil-sharp. UK

NICHE (1997). Report of the Scottish Committee: The Garrick report. Middlesex, National Committee of Enquiry into Higher Education (NICHE).

Olssen, M. and Peters, M. A. (2005). "Neoliberalism, higher education and the knowledge economy: from the free market to knowledge capitalism." Journal of Education Policy 20(3): 313 - 345.

Phillips, M. S. (2004). "Distance and Historical Representation " History Workshop Journal 57(1): 123-141.

Pinker, S. (2002). The Blank Slate: The Modern Denial of Human Nature. Allen Lane. Kent

Raffe, D. (2007). "Making Haste Slowly: the evolution of a unified qualifications framework in Scotland." European Journal of Education 42(4): 485 - 502.

Randall, J. (2000). Why I think degree classification should be abolished. The Times Higher Education Supplement.

Rogers, E. M. (1995). Diffusion of Innovations. The Free Press. New York

Rowland, S. (2000). The enquiring university teacher. Society for Research into Higher Education \& Open University Press. Buckingham [England]; Philadelphia

Rura-Polley, T. and Clegg, S. (1999). "Managing Collaborative Quality: A Challenging Innovation." Creativity and Innovation Management 8: 37-47.

SCQF (2001). An Introduction to the Scottish Credit and Qualifications Framework, Scottish Executive.

Thompson, P., Warhurst, C., Callaghan, G. (2001). "Ignorant Theory and Knowledgeable Workers: Interrogating the connections between Knowledge, Skills and Services." Journal of Management Studies, Special Issue: Knowledge Management: Concepts and Controversies 38(7): 923-942.

Torrance, H. (2006). Research Quality and Research Governance in the United Kingdom: From methodology to management. Qualitative inquiry and the conservative challenge: Confronting methodological fundamentalism. N. K. Denzin and M. D. Giardina. Left Coast Press Walnut Creek: 127-148.

Toulmin, S. E. and Goodfield, J. (1965). The discovery of time. Harmondsworth Eng: Penguin.

Wolfram Cox, J. R., Mann, L. and Samson, D. (1997). "Benchmarking as a mixed metaphor: Disentangling assumptions of competition and collaboration." Journal of Management Studies 34(2): 285 - 314.

Word count including abstract and references: 7,389 (originally 8593) 